\title{
Relationships between Cognitive Performance, Neuroimaging and Vascular Disease: The DHS-MIND Study
}

\author{
Fang-Chi Hsu ${ }^{a, b}$ Laura M. Raffield ${ }^{b-d} \quad$ Christina E. Hugenschmidt ${ }^{e}$ \\ Amanda Cox ${ }^{b, d, j}$ Jianzhao Xub, d J. Jeffery Carr ${ }^{i}$ Barry I. Freedman ${ }^{b, d, f}$ \\ Joseph A. Maldjian' ${ }^{g}$ Jeff D. Williamson ${ }^{\mathrm{e}}$ Donald W. Bowden ${ }^{\mathrm{b}, \mathrm{d}, \mathrm{h}}$ \\ ${ }^{a}$ Department of Biostatistical Sciences, ${ }^{b}$ Center for Diabetes Research, 'Molecular Genetics and Genomics Program, \\ ${ }^{\mathrm{d}}$ Center for Human Genomics, and ${ }^{\mathrm{D}}$ Department of Internal Medicine, Section on Gerontology and Geriatric Medicine, \\ ${ }^{f}$ Department of Internal Medicine - Section on Nephrology, Departments of ${ }^{9}$ Radiology and hiochemistry, Wake \\ Forest School of Medicine, Winston-Salem, N.C., 'Department of Radiology and Radiological Sciences, Vanderbilt \\ University, Nashville, Tenn., USA; 'ं Molecular Basis of Disease, Griffith University, Southport, Brisbane, Qld., Australia
}

\section{Key Words}

Cognitive testing $\cdot$ Neuroimaging $\cdot$ Coronary artery calcified plaque $\cdot$ Type 2 diabetes · Vascular disease

\begin{abstract}
Background: Type 2 diabetes mellitus increases the risk of cognitive decline and dementia, and elevated burdens of vascular disease are hypothesized to contribute to this risk. These relationships were examined in the Diabetes Heart Study-MIND using a battery of cognitive tests, neuroimaging measures and subclinical cardiovascular disease (CVD) burden assessed by coronary artery calcified (CAC) plaque. We hypothesized that CAC would attenuate the association between neuroimaging measures and cognition performance. Methods: Associations were examined using marginal models in this family-based cohort of 572 European Americans from 263 families. All models were adjusted for age, gender, education, type 2 diabetes and hypertension, with some neuroimaging measures additionally adjusted for intracranial volume. Results: Higher total brain volume was associated with better performance on the Digit Symbol Substitution Task and Semantic Fluency (both $p \leq 7.0 \times 10^{-4}$ ). Higher gray matter volume was associated with better performance
\end{abstract}

(C) 2015 S. Karger AG, Base

0251-5350/15/0451-0001\$39.50/0 on the Modified Mini-Mental State Examination and Semantic Fluency (both $p \leq 9.0 \times 10^{-4}$ ). Adjusting for CAC caused minimal changes to the results. Conclusions: Relationships exist between neuroimaging measures and cognitive performance in a type 2 diabetes-enriched European American cohort. Associations were minimally attenuated after adjusting for subclinical CVD. Additional work is needed to understand how subclinical CVD burden interacts with other factors and impacts relationships between neuroimaging and cognitive testing measures.

(c) 2015 S. Karger AG, Basel

\section{Introduction}

Type 2 diabetes mellitus is associated with acceleration of mild age-related declines in a variety of cognitive domains and increased risk of overt dementia [1]. Similarly, changes in the brain in individuals with type 2 diabetes, assessed using MRI-derived neuroimaging measures, including increased white matter lesion volume, reduced brain volume and reduced white matter fractional anisotropy have been reported [2-5]. Cardiovascular disease (CVD) is significantly elevated in people with type 2 dia-

\section{KARGER 125}

E-Mail karger@karger.com www.karger.com/ned
Dr. Fang-Chi Hsu

Department of Biostatistical Sciences, Division of Public Health Sciences Wake Forest School of Medicine, Medical Center Boulevard Winston Salem, NC 27157 (USA)

E-Mail fhsu@ wakehealth.edu 
betes. Both clinical and subclinical CVD have been hypothesized as causal factors in the increased risk of dementia and cognitive decline in people with type 2 diabetes. CVD may be associated to both neuroimaging measures and cognitive tests and may also influence relationships between these measures. Vascular calcified plaque, frequently measured by CT as coronary artery calcified plaque (CAC), is a well-documented independent predictor of CVD events and mortality [6-12] in people with and without diabetes. CAC is a measure of vascular disease burden; individuals affected by type 2 diabetes tend to have higher vascular calcified plaque than the non-diabetic controls [13].

The Diabetes Heart Study (DHS)-MIND is a single-center, family-based study that assessed measures of cognitive performance, neuroimaging and subclinical CVD in a European American population with extensive type 2 diabetes. This study population was chosen based on the high burden of CAC in participants. Our prior work found that $\mathrm{CAC}$ attenuates the association between cognition and type 2 diabetes in tasks that are associated with type 2 diabetes, and it is also associated with cognitive performance on other tests (e.g. Rey Auditory-Verbal Learning Task (RAVLT)) independent of type 2 diabetes [14]. Here, associations between tests of multiple cognitive domains, neuroimaging measures and $\mathrm{CAC}$ were examined. We assessed whether CAC mediated the association between cognitive performance and neuroimaging measures and hypothesized that CAC would attenuate these relationships.

\section{Materials and Methods}

\section{Study Design and Sample}

Participants included individuals enrolled in the DHS, designed to identify genetic and epidemiological factors contributing to CVD risk in type 2 diabetes $[15,16]$. Participants were siblings concordant for type 2 diabetes without advanced renal insufficiency (baseline serum creatinine concentration $<2.0 \mathrm{mg} / \mathrm{dl}$ ) and, where possible, their unaffected siblings. Participants were recruited from internal medicine and endocrinology clinics and the community from 1998 through 2006 in western North Carolina. Ascertainment and recruitment have been described in detail [1518]. Type 2 diabetes-affected participants were diagnosed after the age of 35 years and treated with changes in diet and exercise and/ or insulin or oral agents in the absence of a history of ketoacidosis or initial treatment solely with insulin. Diabetes diagnosis was confirmed by measurement of fasting glucose and glycated hemoglobin Alc at the examination visit. Extensive measurements of CVD risk factors, including CT-based measures of vascular calcified plaque, were obtained during baseline exams from 1998 to 2006.

The DHS-MIND is an ancillary study to the DHS. It was initiated in 2008 to perform cognitive testing and neuroimaging to in- vestigate the risk factors for cognitive decline in the cohort enriched for type 2 diabetes. Participants from the original DHS investigation were re-examined on average of $6.7 \pm 1.6$ years after their initial visit. Participant examinations were conducted in the General Clinical Research Center of the Wake Forest Baptist Medical Center. A total of 893 European American participants were recruited: 572 participants returning from the initial DHS and 321 newly examined. Returning participants had data from the baseline exam, including measures of subclinical CVD $(n=572)$. The 321 newly recruited participants generally had neuroimaging and cognitive test data, but not CT-based vascular imaging. Depression was measured in 429 (of 572) participants using the Center for Epidemiologic Studies Depression (CES-D) Scale 10 item measure that was considered to have high sensitivity and specificity in patients with diabetes [19]. Study protocols were approved by the Institutional Review Board of the Wake Forest School of Medicine. All participants provided written informed consent prior to participation.

\section{CAC Plaque}

Subclinical CVD was assessed by measurement of CAC vascular bed with calcium scores calculated as described [16]. Briefly, all cardiac CT examinations were performed on a single-slice helical CT or a 4-channel multidetector CT with cardiac gating and 500 ms temporal resolution (HiSpeed LX and LightSpeed QXi with the SmartScore Cardiac scan package; General Electric Medical Systems, Waukesha, Wis., USA). After a scout image of the chest, the heart was imaged during suspended respiration at end inspiration. Scan parameters were $3 \mathrm{~mm}$ slice thickness, $26 \mathrm{~cm}$ display field of view (FOV), retrospective cardiac gating, $120 \mathrm{kV}, 240 \mathrm{~mA}$ and CT scan pitch adjusted to heart rate for the single-slice system and 2.5 $\mathrm{mm}$ slice thickness in 4-slice mode, $26 \mathrm{~cm}$ display field of view, prospective cardiac gating at $50 \%$ of the RR interval, $120 \mathrm{kV}$ and $240 \mathrm{~mA}$ for the multidetector CT.

\section{Cognitive Testing}

Participants were administered a battery of cognitive tests as previously described [14]. Global cognitive function was assessed with the Modified Mini-Mental State Examination (3MSE), a measure clinically used to assess dementia with scores ranging from 0 to 100 [20]. The Digit Symbol Substitution Task (DSST) was used as a measure of processing speed and to a lesser extent, working memory, reported here as the number of correct responses within 2 min [21]. The Stroop Task (Stroop) was used to test executive function and was reported here as the difference in response times between subtest 2 and subtest 3 [22]. Verbal memory was tested with the RAVLT, a 15-item word-list recall task [23]. Here, we reported the total number of words recalled across the first 5 trials. Phonemic fluency was measured via the Controlled Oral Word Association Task, reported here as the sum of words generated in a minute for 3 different letters (F, A and S). Semantic fluency was measured by asking participants to generate words related to 2 different categories (kitchen and animals) in a minute, and the sum of these is used for analysis [24, 25].

Participants were not excluded for 3MSE scores or other indices of cognitive function indicative of mild cognitive impairment or dementia. Forty-two participants were part of a pilot feasibility study and did not complete the tasks for evaluating phonemic or semantic fluency. Seven participants who reported being color blind or missed a significant number of questions on the colornaming portion of the task were excluded from the Stroop task. 
DSST scores were missing for 3 participants due to problems with writing $(n=1)$ and vision $(n=2)$. The RAVLT was not completed by 2 participants and 3MSE was not completed by 1 participant. For the 3MSE, DSST, RAVLT and phonemic and semantic fluency, higher scores indicate better cognitive performance; for the Stroop Task, lower scores indicate better performance.

\section{Neuroimaging}

MRI Acquisition

MRI was performed on a 1.5-T GE EXCITE HD scanner with twin-speed gradients using a neurovascular head coil (GE Healthcare, Milwaukee, Wis., USA). A 3D volumetric Inversion Recovery SPGR sequence was used to obtain high-resolution T1 anatomic images (repetition time $(\mathrm{TR})=7.36 \mathrm{~ms}$, echo time $(\mathrm{TE})=2.02 \mathrm{~ms}$, inversion time $(\mathrm{TI})=600 \mathrm{~ms}$, fractional anisotropy $(\mathrm{FA})=20 \mathrm{de}-$ grees, 124 slices, FOV $=24 \mathrm{~cm}$, matrix size $=256 \times 256,1.5-\mathrm{mm}$ slice thickness). Fluid-attenuated inversion recovery (FLAIR) images were acquired in the axial plane $(\mathrm{TR}=8,002 \mathrm{~ms}, \mathrm{TE}=101.29$ $\mathrm{ms}, \mathrm{TI}=2,000 \mathrm{~ms}, \mathrm{FA}=90$ degrees, $\mathrm{FOV}=24 \mathrm{~cm}$, matrix size $=$ $256 \times 256,3-\mathrm{mm}$ slice thickness). Echo-planar imaging with $25 \mathrm{di}$ rections was used to perform whole brain diffusion tensor imaging $(\mathrm{DTI} ; \mathrm{TR}=16,000, \mathrm{TE}=84.9, \mathrm{FA}=90, \mathrm{~b}$ value $=0 / 1,000, \mathrm{FOV}=$ $280 \mathrm{~cm}$, matrix size $=256 \times 256,3-\mathrm{mm}$ slice thickness). A Q2TIPSFAIR sequence, as previously described, was used to generate quantitative cerebral blood flow (CBF) maps [26]. This sequence generates 60 tag and control image pairs. Imaging parameters are TE 28 $\mathrm{ms}, \mathrm{TI}_{1}-800 \mathrm{~ms}, \mathrm{TI}_{1} \mathrm{~s} 1,200 \mathrm{~ms}$, TI $2,000 \mathrm{~ms}$, TR 3,000 ms, receiver bandwidth $62.5 \mathrm{kHz}$, flip angle 90 degrees, FOV $24 \mathrm{~cm}$ (frequency) $\times 18 \mathrm{~cm}$ (phase), an acquisition matrix $64 \times 48$ (11 slices, $8 \mathrm{~mm}$ thickness, $0 \mathrm{~mm}$ slice gap) and frequency encoding direction anterior/posterior. A bipolar diffusion gradient with an equivalent $\mathrm{b}$ value of $5.25 \mathrm{~mm}^{2} / \mathrm{s}$ was added to suppress intra-arterial spins [27].

\section{Image Segmentation}

Structural T1 images were segmented into gray matter, white matter and cerebrospinal fluid (CSF), normalized to Montreal Neurologic Imaging (MNI) space, and modulated with the Jacobian determinants (non-linear components only) of the warping procedure to generate volumetric tissue maps using the Dartel high-dimensional warping and the SPM8 [28] new segment procedure as implemented in the VBM8 toolbox (http://dbm.neuro. uni-jena.de/vbm.html). This modulation step did not include the affine component of the normalization parameters, thereby correcting the volumetric tissue maps for total intracranial volume (ICV). ICV (gray matter volume (GMV) + white matter volume $(\mathrm{WMV})+\mathrm{CSF})$, total brain volume (TBV) $(\mathrm{GMV}+\mathrm{WMV}), \mathrm{GMV}$ and WMV were determined from the VBM8 automated segmentation procedure, which outputs values for native space total GMV, WMV and CSF volume. The normalized gray and white matter segmentation maps (without modulation) were binarized at a probability threshold of 0.5 to create segmentation masks for use in generating the tissue-specific measures of diffusion and CBF.

\section{Diffusion Tensor Processing}

FSL was used to perform diffusion tensor pre-processing [29]. Eddy current correction of the diffusion tensor images was performed using FSL dti_eddy by normalizing each image to the baseline (B0) image using the mutual information registration algorithm. The Camino software package was used to compute the diffusion tensor image (www.camino.org.uk). The resulting tensor images were converted to NIfTI symmetric positive orientation using the DTI ToolKit (DTI-TK) (http://www.nitrc.org/projects/ dtitk). DTI scalar metrics, including FA and mean diffusivity (MD), were computed using DTI-TK. DTI scalars were normalized to MNI space by co-registering the MD image to the T1 structural data using SPM8 and then combining this transformation matrix with the parameters computed in the VBM8 normalization procedure. The global MD and FA measures analyzed here (MD white matter (WMMD), MD gray matter (GMMD), FA white matter (WMFA) and FA gray matter (GMFA)) were calculated based on a white matter segmentation mask generated from the VBM8 segmentation procedure from the structural T1 images applied to the DTI scalar images.

\section{CBF Processing}

Perfusion images were generated using a previously described fully automated data processing pipeline [30]. Quantitative data processing includes data cleaning (removal of individual images with noise spikes, poor tissue segmentation or severe motion artifact), re-alignment (separately for label and control images), spatial smoothing and calculation of mean CBF maps; our methods and experience with this technique has been well documented [3032]. The CBF maps were normalized to MNI space by co-registering to the T1 structural data using SPM8 and then combining this transformation matrix with the parameters computed in the VBM8 normalization procedure, allowing derivation of the gray matter CBF (GMCBF) measure analyzed. Two participants with CBF below $7.9 \mathrm{ml} / 100 \mathrm{~g}$ of tissue/min (biological limit) were removed [33].

\section{White Matter Lesion Segmentation}

White matter lesion segmentation was performed using the lesion segmentation toolbox [34] for SPM8 at a threshold (k) of 0.25. We previously validated the lesion segmentation toolbox for use in the DHS-MIND with a sample of 100 participants against expert manual segmentation, as well as identifying the optimum threshold in this population [35]. Normalization to MNI space was accomplished by co-registration with the structural T1 and applying the normalization parameters computed in the VBM8 segmentation procedure. The total white matter lesion volume (WMLV) measure used in these analyses was determined by summing the binary lesion maps and multiplying by the voxel volume. Neuroimaging data for some participants could not be acquired for a number of reasons and contraindications to MRI: claustrophobia $(\mathrm{n}=27)$, large body size $(\mathrm{n}=14)$, non-MRI compatible implant $(n=1)$, pacemaker $(n=17)$, stent [6], metal in the body (e.g. earrings; $n=10$ ) and miscellaneous (e.g. tissue expander, etc.; $n=9$ ).

\section{Statistical Analyses}

Statistical analysis was completed using SAS software, version 9.3 (SAS Institute, Cary, N.C., USA). Summary statistics such as means, SDs, medians and ranges were computed for the continuous characteristics, and percentages were computed for discrete characteristics. Imaging variables and cognitive testing data were collected in the DHS-MIND sample. However, calcified plaque variables were only available for the 572 participants in the DHS baseline examination. The primary analysis, studying the mediation effect of CAC, was conducted using the subset with CT data collected at the baseline examination. To assess associations between cognitive testing and imaging variables, the entire DHS- 
MIND sample was used to maximize power (online suppl. table S2; for all online suppl. material, see www.karger.com/doi/10.1159/ 000435775).

Stroop, CAC, TBV, WMLV and WMV were log transformed and GMCBF was square-root transformed to approximate the normality assumption. Imaging variables and CAC were standardized for relative importance comparison, allowing the assessment of variables that were more highly associated with cognitive testing data. The following associations were studied using the marginal models incorporating generalized estimating equations approaches: Model 1 explores associations of cognitive testing on neuroimaging variables, Model 2 explores associations of cognitive testing on CAC, Model 3 explores associations of neuroimaging variables on CAC and Model 4 explores associations of cognitive testing on neuroimaging variables after adjusting for CAC. Imaging variables were adjusted in Models 1 and 4 one at a time. Cognitive testing data were treated as the dependent variables in Models 1, 2 and 4 and were not standardized for ease of interpretation. Imaging variables were treated as the dependent variables in Model 3. The comparison between Model 1 and Model 4 was our primary focus. However, we further examined Models 2 and 3 in this type 2 diabetes-enriched European American cohort. Marginal models account for familial correlation using a sandwich estimator of the variance under exchangeable correlation. All models were adjusted for age, gender, educational attainment (not adjusted when exploring the association between neuroimaging and CAC), type 2 diabetes status and hypertension, with models examining TBV, WMLV, GMV and WMV additionally adjusted for ICV. A Bonferroni correction was used to correct for multiple comparisons.

The following sensitivity analyses were performed. First, because depression may affect the performance on cognitive testing, the association analyses (relating imaging measures to cognitive testing (Model 1), relating CAC to cognitive testing (Model 2), relating CAC and imaging to cognitive testing (Model 4)) were further adjusted for depression score. This analysis was treated as a sensitivity analysis, because only $75 \%$ of the sample had data on depression scores. Second, more than $80 \%$ of the sample had type 2 diabetes. Whether the association between neuroimaging and cognitive testing in the diabetes group was the same as that in the non-diabetes group was assessed by performing the analysis (Model 4) stratified by diabetes status.

\section{Results}

The DHS collected data on CVD risk factors from 1998 to 2006, including measures of vascular calcified plaque. The DHS-MIND subsequently collected cognitive testing and neuroimaging data from 893 European Americans from 2008 to 2013, including 572 from the original DHS sample. The demographic characteristics for the entire DHS-MIND sample $(n=893)$ and the subset from the baseline examination $(\mathrm{n}=572)$ are listed in table 1 . With the exception of measures of lipids and CAC, all data are from the DHS-MIND visit. Demographic factors, cognitive performance and imaging measures for the DHS baseline subset were broadly similar to those for the whole sample. The baseline DHS sample was slightly older (1.5 years) and had slightly lower type 2 diabetes prevalence (80.9\%) and educational attainment (28.3\% greater than high school). In addition, the baseline sample tended to use less anti-diabetic medication (67.1 vs. $73.2 \%)$ but more cholesterol-lowering (53.7 vs. $48.3 \%)$ and anti-hypertensive medication (73.1 vs. $67.4 \%$ ).

Cognitive testing demonstrated substantial heterogeneity in performance; scores ranged from levels indicative of mild dementia (3MSE <77) to above average. Overall, mean and median scores on cognitive tests were slightly lower than expected in the general population. The baseline sample had lower scores on the 3MSE, DSST, phonemic and semantic fluency, but higher Stroop scores, compared to the entire DHS-MIND sample, indicative of slightly poorer cognitive testing performance in the baseline sample. Furthermore, the baseline sample had lower TBV, GMV and ICV, but had higher WMFA, GMFA and GMCBF compared to the entire DHS-MIND sample.

\section{Association of Cognitive Testing and Neuroimaging Variables (Model 1)}

The association between cognitive testing and imaging variables (table 2) included only individuals from the baseline samples. Analyses were adjusted for age, gender, educational attainment, type 2 diabetes and hypertension, with TBV, WMLV, GMV and WMV additionally adjusted for ICV. Correcting for multiple comparisons, significance was accepted for $\alpha \leq 0.0014$.

TBV (GMV + WMV) was positively associated with DSST $\left(\mathrm{p}=2.4 \times 10^{-4}\right)$ and with semantic fluency $(\mathrm{p}=7.0 \times$ $10^{-4}$ ), meaning that greater brain volume was associated with better processing speed performance. Per SD increase of TBV and DSST would increase by 9.89 correct responses (equivalent to 18.9 years of aging effect in the opposite direction) and semantic fluency would increase by 5.00 named items (equivalent to 24.0 years of aging effect in the opposite direction). GMV was associated with performance on the $3 \mathrm{MSE}\left(\mathrm{p}=7.0 \times 10^{-4}\right)$ and semantic fluency $\left(\mathrm{p}=9.0 \times 10^{-4}\right)$. Per SD increase of GMV and $3 \mathrm{MSE}$ would increase 2.86 points (equivalent to 19.9 years of aging effect in the opposite direction) and semantic fluency would increase by 2.46 named items (equivalent to 11.8 years of aging effect in the opposite direction). WMV was not significantly associated with any cognitive test.

White matter integrity was assessed using WMLV segmentation from the FLAIR images and FA from DTI analysis, which can detect subclinical changes in white matter microstructure. Both WMLV $\left(\mathrm{p}=1.0 \times 10^{-4}\right)$ and 
Table 1. Demographic characteristics of all European American participants recruited to the DHS-MIND study ( $\mathrm{n}=893$ ) and the subgroup previously enrolled in initial examination $(\mathrm{n}=572)$

\begin{tabular}{|c|c|c|c|c|c|}
\hline & \multicolumn{2}{|c|}{ DHS-MIND sample $(\mathrm{n}=893)^{3}$} & \multicolumn{2}{|c|}{ Initial enrollment $(\mathrm{n}=572)^{3}$} & $\mathrm{p}$ value $\mathrm{e}^{2}$ \\
\hline Age, years & $65.8 \pm 9.7$ & $66.3(37.7-93.2)$ & $67.3 \pm 8.9$ & $67.5(41.3-89.2)$ & $1.5 \times 10^{-9}$ \\
\hline Gender, female, \% & 52.9 & & 54.6 & & 0.054 \\
\hline $\mathrm{BMI}, \mathrm{kg} / \mathrm{m}^{2}$ & $32.5 \pm 6.7$ & $31.4(14.6-59.0)$ & $31.6 \pm 6.6$ & $30.4(17.6-58.4)$ & $6.3 \times 10^{-6}$ \\
\hline \% smoking (current or past) & 54.6 & & 55.9 & & 0.746 \\
\hline Diastolic blood pressure, $\mathrm{mm} \mathrm{Hg}$ & $71.4 \pm 10.4$ & $71(39-121)$ & $70.2 \pm 10.4$ & $70(39-121)$ & $1.4 \times 10^{-6}$ \\
\hline \multirow[t]{2}{*}{ Self-reported history of prior CVD, \% CES-D score } & 34.9 & & 33.5 & & 0.991 \\
\hline & $7.5 \pm 5.3$ & $6(0-29)$ & $7.1 \pm 5.2$ & $6(0-29)$ & 0.021 \\
\hline \multicolumn{6}{|l|}{ Type 2 diabetes } \\
\hline Type 2 diabetes affected, $\%$ & 87.6 & & 80.9 & & $4.6 \times 10^{-18}$ \\
\hline Diabetes duration, years & $15.4 \pm 7.7$ & $13.6(0.4-45.0)$ & $16.6 \pm 7.0$ & $14.7(1.9-44.5)$ & $7.4 \times 10^{-7}$ \\
\hline \multicolumn{6}{|l|}{ Medication use, \% } \\
\hline Anti-diabetic medication ${ }^{1}$ & 73.2 & & 67.1 & & $2.1 \times 10^{-6}$ \\
\hline Cholesterol-lowering medication & 52.4 & & 53.7 & & 0.184 \\
\hline Anti-hypertensive medication & 67.4 & & 73.1 & & $1.3 \times 10^{-5}$ \\
\hline \multicolumn{6}{|l|}{ Education, \% } \\
\hline Less than high school & 14.8 & & 17.8 & & $4.9 \times 10^{-10}$ \\
\hline High school & 47.7 & & 53.9 & & \\
\hline Greater than high school & 37.5 & & 28.3 & & \\
\hline \multicolumn{6}{|l|}{ Lipids } \\
\hline Total cholesterol, mg/dl & & & $185.5 \pm 41.8$ & $181(65-391)$ & \\
\hline HDL cholesterol, mg/dl & & & $43.4 \pm 11.6$ & $42(14-102)$ & \\
\hline LDL cholesterol, mg/dl & & & $104.9 \pm 32.1$ & $104(14-221)$ & \\
\hline Triglycerides & & & $192.9 \pm 128.8$ & $161(30-1,310)$ & \\
\hline \multicolumn{6}{|l|}{ Imaging } \\
\hline $\mathrm{TBV}, \mathrm{ml}$ & $1,092 \pm 112$ & $1,080(775-1,448)$ & $1,085 \pm 113$ & $1,072(775-1,448)$ & 0.009 \\
\hline WMLV, ml & $4.5 \pm 8.3$ & $1.5(0-103.3)$ & $4.4 \pm 7.1$ & $1.6(0-59.6)$ & 0.060 \\
\hline $\mathrm{GMV}, \mathrm{ml}$ & $519 \pm 54$ & $517(373-709)$ & $511 \pm 51$ & $508(375-660)$ & $1.4 \times 10^{-8}$ \\
\hline WMV, ml & $573 \pm 70$ & $568(400-815)$ & $574 \pm 71$ & $569(400-815)$ & 0.603 \\
\hline Total ICV, ml & $1,350 \pm 138$ & $1,337(985-1,759)$ & $1,340 \pm 139$ & $1,328(985-1,759)$ & 0.002 \\
\hline WMFA & $0.35 \pm 0.03$ & $0.35(0.26-0.42)$ & $0.36 \pm 0.02$ & $0.36(0.29-0.42)$ & $9.4 \times 10^{-20}$ \\
\hline GMFA & $0.20 \pm 0.02$ & $0.20(0.14-0.35)$ & $0.21 \pm 0.02$ & $0.21(0.15-0.26)$ & $9.5 \times 10^{-18}$ \\
\hline WMMD & $0.79 \pm 0.05$ & $0.79(0.63-0.95)$ & $0.79 \pm 0.05$ & $0.79(0.63-0.95)$ & 0.162 \\
\hline GMMD & $1.09 \pm 0.09$ & $1.08(0.68-1.38)$ & $1.09 \pm 0.09$ & $1.09(0.80-1.38)$ & 0.104 \\
\hline GMCBF, $\mathrm{ml} / 100 \mathrm{~g}$ of tissue/min & $45.0 \pm 17.3$ & $42.8(9.0-134.9)$ & $46.7 \pm 18.2$ & $44.1(9.1-134.9)$ & $5.9 \times 10^{-5}$ \\
\hline
\end{tabular}

${ }^{1}$ Either oral hypoglycemic medications or insulin. ${ }^{2}$ The comparison between those who were in the initial enrollment and those who were not using marginal models. ${ }^{3}$ Some variables have missing data, so the sample size for each variable is listed below. The sample size for DHS-MIND sample: BMI 891; CES-D score 749; type 2 diabetes duration 745; glucose and HbA1c 845; 3MSE 892; DSST 889; Stroop 883; RAVLT 891; semantic and phonemic fluency 849; TBV 717; WMLV 742; GMV, WMV, and ICV 718; WMFA, GMFA, WMMD and GMMD 671; GMCBF 615. The sample size for the initial enrollment cohort: BMI 571; CES-D score 429; type 2 diabetes duration 429; glucose and HbA1c 527; coronary calcified plaque 532; 3MSE 571; DSST 569; Stroop 565; RAVLT 570; semantic and phonemic fluency 529; WMLV 448; GMV, WMV, TBV and ICV 480; WMFA, GMFA, WMMD and GMMD 476; GMCBF 449.

$\mathrm{BMI}=$ Body mass index; HbAlc $=$ hemoglobin A1c.

Association between Cognitive Testing,

Imaging and Subclinical CVD
Neuroepidemiology 2015;45:1-11 DOI: $10.1159 / 000435775$ 
Table 2. Association between cognitive performance and brain imaging for the subset with a baseline examination ${ }^{1}$

\begin{tabular}{|c|c|c|c|c|c|c|c|}
\hline Variable & & $3 \mathrm{MSE}$ & DSST & Stroop $^{2}$ & RAVLT & $\begin{array}{l}\text { Phonemic } \\
\text { fluency }\end{array}$ & $\begin{array}{l}\text { Semantic } \\
\text { fluency }\end{array}$ \\
\hline $\mathrm{TBV}^{2}$ & $\begin{array}{l}\beta \text { estimate } \\
(95 \% \mathrm{CI}) \\
\mathrm{p} \text { value }\end{array}$ & $\begin{array}{l}4.43 \\
(0.17 \text { to } 8.69) \\
0.042\end{array}$ & $\begin{array}{l}9.89 \\
(4.62 \text { to } 15.17) \\
2.4 \times 10^{-4}\end{array}$ & $\begin{array}{l}-0.17 \\
(-0.49 \text { to } 0.15) \\
0.296\end{array}$ & $\begin{array}{l}3.86 \\
(0.72 \text { to } 6.99) \\
0.016\end{array}$ & $\begin{array}{l}5.84 \\
(1.29 \text { to } 10.31) \\
0.012\end{array}$ & $\begin{array}{l}5.00 \\
(2.11 \text { to } 7.90) \\
7.0 \times 10^{-4}\end{array}$ \\
\hline $\mathrm{WMLV}^{2}$ & $\begin{array}{l}\beta \text { estimate } \\
(95 \% \mathrm{CI}) \\
\mathrm{p} \text { value }\end{array}$ & $\begin{array}{l}-0.23 \\
(-0.93 \text { to } 0.47) \\
0.518\end{array}$ & $\begin{array}{l}-2.55 \\
(-3.83 \text { to }-1.26) \\
1.0 \times 10^{-4}\end{array}$ & $\begin{array}{l}0.02 \\
(-0.04 \text { to } 0.07) \\
0.511\end{array}$ & $\begin{array}{l}-0.95 \\
(-1.88 \text { to }-0.02) \\
0.046\end{array}$ & $\begin{array}{l}-1.07 \\
(-2.30 \text { to } 0.16) \\
0.087\end{array}$ & $\begin{array}{l}-1.20 \\
(-2.02 \text { to }-0.39) \\
0.004\end{array}$ \\
\hline GMV & $\begin{array}{l}\beta \text { estimate } \\
(95 \% \mathrm{CI}) \\
\mathrm{p} \text { value }\end{array}$ & $\begin{array}{l}2.86 \\
(1.21 \text { to } 4.52) \\
7.0 \times 10^{-4}\end{array}$ & $\begin{array}{l}3.01 \\
(0.64 \text { to } 5.39) \\
0.013\end{array}$ & $\begin{array}{l}-0.05 \\
(-0.18 \text { to } 0.08) \\
0.463\end{array}$ & $\begin{array}{l}2.13 \\
(0.43 \text { to } 3.82) \\
0.014\end{array}$ & $\begin{array}{l}2.77 \\
(0.62 \text { to } 4.91) \\
0.011\end{array}$ & $\begin{array}{l}2.46 \\
(1.01 \text { to } 3.91) \\
9.0 \times 10^{-4}\end{array}$ \\
\hline $\mathrm{WMV}^{2}$ & $\begin{array}{l}\beta \text { estimate } \\
(95 \% \mathrm{CI}) \\
\mathrm{p} \text { value }\end{array}$ & $\begin{array}{l}-0.28 \\
(-2.11 \text { to } 1.55) \\
0.767\end{array}$ & $\begin{array}{l}2.66 \\
(-0.65 \text { to } 5.97) \\
0.115\end{array}$ & $\begin{array}{l}-0.06 \\
(-0.19 \text { to } 0.06) \\
0.314\end{array}$ & $\begin{array}{l}-0.09 \\
(-2.24 \text { to } 2.06) \\
0.935\end{array}$ & $\begin{array}{l}0.72 \\
(-2.28 \text { to } 3.72) \\
0.639\end{array}$ & $\begin{array}{l}0.44 \\
(-1.45 \text { to } 2.32) \\
0.651\end{array}$ \\
\hline $\mathrm{GMCBF}^{2}$ & $\begin{array}{l}\beta \text { estimate } \\
(95 \% \mathrm{CI}) \\
\text { p value }\end{array}$ & $\begin{array}{l}-0.70 \\
(-1.30 \text { to }-0.11) \\
0.021\end{array}$ & $\begin{array}{l}0.29 \\
(-0.89 \text { to } 1.46) \\
0.633\end{array}$ & $\begin{array}{l}-0.04 \\
(-0.08 \text { to } 0.01) \\
0.131\end{array}$ & $\begin{array}{l}0.62 \\
(-0.20 \text { to } 1.44) \\
0.138\end{array}$ & $\begin{array}{l}0.81 \\
(-0.27 \text { to } 1.88) \\
0.140\end{array}$ & $\begin{array}{l}0.41 \\
(-0.44 \text { to } 1.25) \\
0.348\end{array}$ \\
\hline
\end{tabular}

${ }^{1}$ All models adjusted for age, gender, educational attainment, type 2 diabetes and hypertension; TBV, WMLV, GMV and WMV additionally adjusted for ICV.

${ }^{2}$ Stroop, TBV, WMLV and WMV are log transformed. GMCBF is square-root transformed.

WMFA $\left(\mathrm{p}=8.0 \times 10^{-6}\right)$ were associated with DSST. As in previous studies, greater WMLV was associated with poorer scores on the DSST $(\beta=-2.55)$. Increased FA, a marker of white matter health, was associated with better scores on the DSST $(\beta=3.26)$. Higher WMFA was also associated with better performance on the Stroop test $\left(\beta\right.$ estimate $\left.=-0.09, \mathrm{p}=4.6 \times 10^{-4}\right)$. Note that in this study WMFA was included in our main analysis, as this is the most commonly analyzed DTI measure, with global WMFA previously associated with diabetes status [4]. The analyses for WMMD, GMMD and GMFA are presented in online supplementary table $S 1$ for reference.

Online supplementary table S2 summarizes associations between cognitive testing and standardized imaging measures using the entire DHS-MIND sample. As in the subsample with CAC data, TBV was positively associated with DSST $\left(\mathrm{p}=6.0 \times 10^{-6}\right)$ and semantic fluency $(\mathrm{p}=6.0 \times$ $\left.10^{-6}\right)$. In this larger sample, TBV was also positively associated with performance on the RAVLT $\left(\mathrm{p}=6.1 \times 10^{-5}\right)$ and phonemic fluency $\left(\mathrm{p}=1.2 \times 10^{-4}\right)$. GMV was again positively associated with 3 MSE score $\left(\mathrm{p}=7.3 \times 10^{-5}\right)$ and semantic fluency $\left(\mathrm{p}=8.5 \times 10^{-5}\right)$ and, in the larger sample, with DSST performance $\left(\mathrm{p}=2.0 \times 10^{-6}\right)$. As in the smaller sample, WMV was not associated with any cognitive measures. WMLV was again negatively associated with DSST score $\left(\mathrm{p}=2.2 \times 10^{-7}\right)$, and, in the larger sample, with RAVLT $\left(\mathrm{p}=9.9 \times 10^{-5}\right)$, phonemic fluency $(\mathrm{p}=6.8 \times$ $\left.10^{-4}\right)$ and semantic fluency $\left(\mathrm{p}=2.0 \times 10^{-6}\right)$. WMFA was positively associated with only RAVLT $\left(\mathrm{p}=4.5 \times 10^{-4}\right)$. Thus, analyses of the entire sample $(n=893)$ largely replicate results from the subset with data for CAC, and in many cases, the associations are statistically stronger.

\section{Association of Cognitive Testing and Neuroimaging with Vascular Calcified Plaque (Models 2 and 3)}

The associations between cognitive testing measures and standardized log transformed CAC are presented in table 3. After adjusting for age, gender, educational attainment, type 2 diabetes and hypertension and correcting for multiple comparisons ( $\alpha=0.0083)$, only RAVLT performance was negatively associated with log transformed CAC $(\mathrm{p}=0.003)$. That is, higher log transformed CAC burden was associated with lower word recall, such that 1.27 fewer words (equivalent to 2.9 years of aging ef- 
Table 3. Association between standardized CAC plaque and cognitive function and brain imaging (standardized) for the subset with a baseline examination ${ }^{1}$

\begin{tabular}{lcl}
\hline Variable & $\beta$ estimate $(95 \% \mathrm{CI})$ & p value \\
\hline Cognitive function test & measures & \\
3MSE & $0.09(-0.53$ to 0.71$)$ & 0.776 \\
DSST & $-1.38(-2.58$ to -0.18$)$ & 0.024 \\
Stroop & & 0.104 \\
RAVLT & $0.04(-0.01$ to 0.08$)$ & 0.003 \\
Phonemic fluency & $-1.27(-2.12$ to -0.42$)$ & 0.751 \\
Semantic fluency & $0.17(-0.90$ to 1.24$)$ & 0.034 \\
\hline Imaging measures & $-0.74(-1.43$ to -0.06$)$ & \\
TBV & & \\
WMLV & & $6.0 \times 10^{-6}$ \\
GMV $^{2}$ & $-0.05(-0.07$ to -0.03$)$ & 0.023 \\
WMV $^{2}$ & $0.12(0.02$ to 0.21$)$ & 0.0007 \\
WMFA $_{\text {GMCBF }}^{2}$ & $-0.08(-0.13$ to -0.04$)$ & 0.493 \\
& $-0.01(-0.05$ to 0.03$)$ & 0.679 \\
\hline
\end{tabular}

${ }^{1}$ All cognitive function models adjusted for age, gender, educational attainment, type 2 diabetes and hypertension; All imaging models adjusted for the same covariates except educational attainment; TBV, WMLV, GMV and WMV additionally adjusted for ICV.

${ }^{2}$ Coronary calcified plaque, Stroop, TBV, WMLV and WMV are $\log$ transformed. GMCBF is square-root transformed.

fect in the opposite direction) were recalled for each SD increase of log transformed CAC. Performance on the DSST and semantic fluency were nominally associated $(\mathrm{p}<0.05)$ with CAC burden.

Associations between standardized imaging measures and $\log$ transformed CAC are listed in table 3 , and associations with secondary imaging outcomes are presented in online supplementary table S3. Analyses were adjusted for age, gender, type 2 diabetes, hypertension and, except for FA, adjusted for ICV. After correcting for multiple comparisons $(\alpha=0.0083)$, TBV $(\beta$ estimate $=$ $\left.-0.05, \mathrm{p}=6.0 \times 10^{-6}\right)$ and GMV $(\beta$ estimate $=-0.08, \mathrm{p}=$ $\left.7.0 \times 10^{-4}\right)$ were negatively associated with CAC. That is, higher CAC burden was associated with lower brain volumes.

\section{Association of Cognitive Performance and Imaging}

Variables after Adjusting for Vascular Calcified

Plaque (Model 4)

Next, analyses were performed to assess whether CAC mediates the relationship between cognitive performance and neuroimaging measures. The associations between imaging and cognitive testing measures following adjustment for log transformed CAC (table 4) were very similar to those without the additional CAC adjustment (table 2). After adjusting for CAC burden, TBV remained positively associated with DSST $(\beta$ estimate $=10.01, \mathrm{p}=4.5 \times$ $10^{-4}$ ) and semantic fluency ( $\beta$ estimate $=5.07, \mathrm{p}=0.001$ ) with little change in effect sizes or $\mathrm{p}$ values. GMV was still significantly associated with $3 \mathrm{MSE}$ ( $\beta$ estimate $=2.98, \mathrm{p}=$ $\left.9.3 \times 10^{-4}\right)$; however, the association between GMV and semantic fluency dropped below multiple corrections threshold significance $(\beta$ estimate $=2.16, p=0.004)$. The association between WMLV and DSST was slightly strengthened by adjustment for CAC ( $\beta$ estimate $=-2.71$, $\left.\mathrm{p}=5.1 \times 10^{-5}\right)$, and the associations between WMFA and DSST $\left(\beta\right.$ estimate $\left.=3.20, \mathrm{p}=1.3 \times 10^{-5}\right)$ and the Stroop test $\left(\beta\right.$ estimate $\left.=-0.09, \mathrm{p}=9.8 \times 10^{-4}\right)$ remained significant. In addition, the association between WMFA and semantic fluency was strengthened ( $\beta$ estimate $=1.48$, $\left.\mathrm{p}=8.7 \times 10^{-4}\right)$. Associations with secondary imaging outcomes are presented in online supplementary table S4.

When comparing the regression coefficients between the models with and without CAC adjustment, only the coefficient between GMV and semantic fluency changed over $10 \%$. The regression coefficient changed from 2.46 to 2.16 after adjusting for CAC (12\% reduction) and the $p$ value became non-significant. These results suggest that CAC may not be a significant mediator for the associations between imaging and cognitive testing in the DHSMIND cohort. However, it may mediate the association between GMV and semantic fluency slightly.

\section{Sensitivity Analysis}

To demonstrate the robustness of our results, we performed 2 sensitivity analyses. First, the association analysis further adjusted for CES-D scores showed similar results (data not shown). Second, the analyses stratified by diabetes status (Model 4) are presented in online supplementary table S5A and B. For the diabetes-only analysis, the results were similar to previous results in the full sample. Due to the smaller sample size $(n=463)$, results were somewhat less significant. Previously significant associations with DSST and the association between TBV and semantic fluency remained. In the non-diabetic sample $(n=109)$, the only significant result was observed in the association between WMFA and DSST.

\section{Discussion}

The previous analysis of the DHS-MIND cohort, a type 2 diabetes-enriched study population, indicated that higher levels of subclinical CVD were associated 
Table 4. Association of cognitive performance and brain imaging (standardized) after adjusting for standardized CAC plaque and other covariates for the subset with a baseline examination ${ }^{1}$

\begin{tabular}{|c|c|c|c|c|c|c|c|}
\hline $\begin{array}{l}\text { Imaging } \\
\text { measure }\end{array}$ & & $3 \mathrm{MSE}$ & DSST & Stroop ${ }^{2}$ & RAVLT & $\begin{array}{l}\text { Phonemic } \\
\text { fluency }\end{array}$ & $\begin{array}{l}\text { Semantic } \\
\text { fluency }\end{array}$ \\
\hline $\mathrm{TBV}^{2}$ & $\begin{array}{l}\beta \text { estimate } \\
(95 \% \mathrm{CI}) \\
\mathrm{p} \text { value }\end{array}$ & $\begin{array}{l}4.77 \\
(0.55 \text { to } 8.99) \\
0.027\end{array}$ & $\begin{array}{l}10.01 \\
(4.42 \text { to } 15.59) \\
4.5 \times 10^{-4}\end{array}$ & $\begin{array}{l}-0.16 \\
(-0.50 \text { to } 0.19) \\
0.375\end{array}$ & $\begin{array}{l}3.58 \\
(0.34 \text { to } 6.82) \\
0.030\end{array}$ & $\begin{array}{l}6.23 \\
(1.56 \text { to } 10.91) \\
0.009\end{array}$ & $\begin{array}{l}5.07 \\
(1.95 \text { to } 8.18) \\
0.001\end{array}$ \\
\hline WMLV $^{2}$ & $\begin{array}{l}\beta \text { estimate } \\
(95 \% \mathrm{CI}) \\
\mathrm{p} \text { value }\end{array}$ & $\begin{array}{l}-0.36 \\
(-1.08 \text { to } 0.35) \\
0.321\end{array}$ & $\begin{array}{l}-2.71 \\
(-4.01 \text { to }-1.40) \\
5.1 \times 10^{-5}\end{array}$ & $\begin{array}{l}0.01 \\
(-0.04 \text { to } 0.07) \\
0.679\end{array}$ & $\begin{array}{l}-0.91 \\
(-1.86 \text { to } 0.05) \\
0.063\end{array}$ & $\begin{array}{l}-1.07 \\
(-2.33 \text { to } 0.19) \\
0.096\end{array}$ & $\begin{array}{l}-1.29 \\
(-2.11 \text { to }-0.48) \\
0.002\end{array}$ \\
\hline GMV & $\begin{array}{l}\beta \text { estimate } \\
(95 \% \mathrm{CI}) \\
\mathrm{p} \text { value }\end{array}$ & $\begin{array}{l}2.98 \\
(1.22 \text { to } 4.74) \\
9.3 \times 10^{-4}\end{array}$ & $\begin{array}{l}2.72 \\
(0.25 \text { to } 5.18) \\
0.031\end{array}$ & $\begin{array}{l}-0.03 \\
(-0.16 \text { to } 0.10) \\
0.633\end{array}$ & $\begin{array}{l}1.84 \\
(0.14 \text { to } 3.54) \\
0.034\end{array}$ & $\begin{array}{l}2.70 \\
(0.48 \text { to } 4.91) \\
0.017\end{array}$ & $\begin{array}{l}2.16 \\
(0.69 \text { to } 3.62) \\
0.004\end{array}$ \\
\hline $\mathrm{WMV}^{2}$ & $\begin{array}{l}\beta \text { estimate } \\
(95 \% \mathrm{CI}) \\
\mathrm{p} \text { value }\end{array}$ & $\begin{array}{l}-0.26 \\
(-1.94 \text { to } 1.42) \\
0.763\end{array}$ & $\begin{array}{l}2.81 \\
(-0.54 \text { to } 6.16) \\
0.100\end{array}$ & $\begin{array}{l}-0.07 \\
(-0.20 \text { to } 0.06) \\
0.317\end{array}$ & $\begin{array}{l}0.04 \\
(-2.12 \text { to } 2.20) \\
0.968\end{array}$ & $\begin{array}{l}0.85 \\
(-2.29 \text { to } 3.99) \\
0.597\end{array}$ & $\begin{array}{l}0.71 \\
(-1.18 \text { to } 2.61) \\
0.461\end{array}$ \\
\hline $\mathrm{GMCBF}^{2}$ & $\begin{array}{l}\beta \text { estimate } \\
(95 \% \mathrm{CI}) \\
\text { p value }\end{array}$ & $\begin{array}{l}-0.66 \\
(-1.30 \text { to }-0.02) \\
0.043\end{array}$ & $\begin{array}{l}0.40 \\
(-0.69 \text { to } 1.50) \\
0.469\end{array}$ & $\begin{array}{l}-0.04 \\
(-0.09 \text { to } 0.01) \\
0.121\end{array}$ & $\begin{array}{l}0.75 \\
(-0.05 \text { to } 1.55) \\
0.065\end{array}$ & $\begin{array}{l}0.73 \\
(-0.36 \text { to } 1.81) \\
0.189\end{array}$ & $\begin{array}{l}0.47 \\
(-0.39 \text { to } 1.33) \\
0.282\end{array}$ \\
\hline
\end{tabular}

\footnotetext{
${ }^{1}$ All models adjusted for age, gender, educational attainment, type 2 diabetes, hypertension and coronary calcified plaque; TBV, WMLV, GMV and WMV additionally adjusted for ICV.

${ }^{2}$ Stroop, coronary calcified plaque, TBV, WMLV and WMV are log transformed. GMCBF is square-root transformed.
}

with poorer performance on the DSST, RAVLT and semantic fluency [14]. Here, we investigated whether cognitive function in this cohort was associated with brain imaging outcomes, and whether neuroimaging-cognition relationships were influenced by burden of subclinical CVD. In the subsample where complete data on cognition, imaging and subclinical CVD were available, imaging variables were associated with the $3 \mathrm{MSE}$, DSST, Stroop and semantic fluency. The associations between imaging and cognitive testing measures changed a little after adjusting for CAC. The semantic fluency was the only cognitive task that showed significant changes in association after adjusting for CAC. The effect size for association between GMV and semantic fluency was reduced by $12 \%$ and $\mathrm{p}$ value dropped to non-significance, suggesting the relationships between GMV and semantic fluency may be mediated by subclinical CVD. In addition, the association between WMFA and semantic fluency strengthened slightly to reach statistical significance after accounting for the variance explained by CAC.
These results indicate that both brain imaging measures and subclinical CVD are associated with cognitive performance in a European American cohort with a high prevalence of type 2 diabetes. However, for global cognition (assessed via 3MSE) and processing speed (assessed via DSST), these cognition-neuroimaging associations are not explained by the burden of subclinical CVD (CAC). However, CAC may mediate the association between neuroimaging variables (GMV and WMFA) and semantic fluency. While not statistically significant, there was a trend $(p=0.014)$ for association between the GMV and RAVLT, and the magnitude of this trend was decreased by $14 \%$ after adjusting for CAC, similar to the effects on semantic fluency. Our findings are in concordance with 2 other studies that investigated the relationships between CAC, cognition and neuroimaging measures, although they examined the mediation effect of brain imaging measures in the relationship between CAC and cognitive status instead [36, 37]. Vidal et al. [36] reported that participants with increasing CAC were more likely to have dementia and poorer cognitive 
performance; these relationships were mediated by brain volumes and lesions. Rosano et al. [37] reported that the presence of any MRI abnormalities, including ventricular enlargement, white matter hyperintensities and subcortical brain infarcts, attenuated the association between CAC and abnormal cognitive status in older adults.

There are differences in the significant associations reported here and in our previous report of this cohort. We previously reported that $\mathrm{CAC}$ was associated with poorer performance on the RAVLT, DSST and semantic fluency and that $\mathrm{CAC}$ attenuated the association of type 2 diabetes with performance on these cognitive tests [14]. The main reason for these differences in the association between cognition and CAC is that in this analysis, we applied a correction for multiple comparisons and also the sample size is slightly larger with more data being collected. The previous associations with the RAVLT and DSST were observed, but did not meet the more stringent correction for multiple comparisons. Furthermore, it is worth noting that our sister study with the same study design, but recruiting only African American participants (AA-DHS MIND), did not observe any association between CAC and cognitive testing measures (Barry Freedman, personal communication). The mechanism for the racial difference requires further research.

There is an increasing body of literature reporting the association of CVD risk factors with brain structure and function [36-38]. CAC has been shown to negatively associate with TBV, GMV and WMV and positively associate with WMLV [36]. We observed the associations with TBV and GMV, but not with WMLV and WMV. Differences in neuroimaging methods and sample ascertainment, notably the enrichment for type 2 diabetes in the DHS, may partially explain these discrepancies. No prior studies reported the associations with WMFA and GMCBF; these measures have not been analyzed frequently, however.

Neuroimaging measures such as higher WMLV and lower GMV and WMV have been associated previously with lower scores on cognitive tests, including tests of memory, processing speed and executive function, both in individuals with and without type 2 diabetes and in both cross-sectional and longitudinal studies [39-46]. Factors such as blood pressure and glycemic control may influence these associations. Richard Jennings et al. [47] found that the degree of lowering blood pressure affected the association between cognitive performance and patterns of regional CBF. The ACCORD MIND study [48] showed that there was a significant glucose treatment ef-

Association between Cognitive Testing,

Imaging and Subclinical CVD fect on TBV, but no significant effects on cognitive outcomes. Midlife systolic blood pressure has been found to predict both cognitive function and brain imaging [49]. Diabetes increases risk of cognitive decline and changes in cerebral white matter [44]. In our type 2 diabetes-enriched study population (16.6 year mean diabetes duration), we similarly showed that TBV, WMLV and GMV were associated with cognitive testing including 3MSE, DSST and semantic fluency. In addition, WMFA was associated with DSST and Stroop in the baseline sample and with RAVLT in the whole sample. It has been shown that WMFA is associated with cognitive function in the elderly [50].

For the diabetes-only analysis, the results were similar to previous results in the full sample. Due to the smaller sample size $(\mathrm{n}=463)$, results were less significant. However, the associations still reached the nominal significance level at $\mathrm{p}$ values $<0.05$, because more than $80 \%$ of the study population had diabetes and the previous analysis appears to have been mainly driven by this majority. In addition, non-diabetic participants likely share genetic and environmental effects (and had similar demographic characteristics) as their diabetic siblings. In the smaller non-diabetic analysis $(n=109)$, the only significant result was observed for association between WMFA and DSST. The association of semantic fluency on TBV and WMFA did not reach nominal significance. This analysis suggests that the association of semantic fluency on neuroimaging variables may differ between diabetic and non-diabetic subjects, but requires further study.

This study has several strengths. Prior studies have often evaluated small cohorts and have lacked analysis of multiple neuroimaging and cognitive testing measures. The DHS sample provides a foundation for understanding the potential importance of early intervention to prevent the cognitive decline and devastating brain complications of type 2 diabetes and its associated risk factors, which are increasingly prevalent in older adults. This study also has limitations. First, more than $80 \%$ of participants had type 2 diabetes; so the results may not be generalized to the general population. Second, the initial (baseline) participants were older and less highly educated and had lower body mass index, more hypertension and less type 2 diabetes. As such, their study results should be compared to the full DHS-MIND sample with caution. Third, no causal relationship regarding the mediation effect of vascular calcification can be established due to the cross-sectional design. Fourth, we attempted to perform formal mediation tests using the method developed by Bauer et al. [51]. However, all models did not converge, 
except when phonemic fluency was treated as the dependent variable. The mediation effects (i.e. indirect effects) were not significant on phonemic fluency (all $\mathrm{p}$ values $>0.05$ ); therefore, we did not present these test results in the manuscript.

\section{Conclusion}

Overall, this study demonstrated the multiple relationships between neuroimaging measures and cognitive testing in type 2 diabetes-enriched population. These associations were slightly attenuated, but not eliminated, after adjusting for subclinical CVD, measured as CAC. Additional research is necessary to understand how atherosclerosis interacts with other factors, such as genetic factors and glycemic control, to injure the brain and impair cognitive function.

\section{Acknowledgements and Funding}

This study was supported in part by the National Institutes of Health through R01 HL67348, R01 HL092301, R01 NS058700 (to D.W.B.), R01 NS075107 (to B.I.F. and J.A.M.), F32 DK083214-01 (to C.E.H.), F31 AG044879 (to L.M.R.) and the General Clinical Research Centre of the Wake Forest School of Medicine (M01 RR07122 and F32 HL085989). The authors thank the other investigators, the staff and the participants of the DHS study for their valuable contributions.

\section{Author Contributions}

F.-C.H. analyzed the data and wrote the manuscript; L.M.R. contributed to the statistical analysis and reviewed and edited the manuscript; C.E.H. collected, managed data, reviewed and edited the manuscript; A.C. reviewed and edited the manuscript; J.X. collected and managed data; J.J.C. initially designed the DHS and ascertained and clinically evaluated patients; B.I.F. initially designed the DHS, ascertained and clinically evaluated patients and reviewed and edited the manuscript; J.A.M. collected the neuroimaging data and reviewed and edited the manuscript; J.D.W. collected the cognitive performance data; D.W.B. led the DHS and reviewed and edited the manuscript. F.-C.H. is the guarantor of this work and, as such, had full access to all the data in the study and takes responsibility for the integrity of the data and the accuracy of the data analysis.

\section{Disclosure Statement}

The authors declare no conflicts of interest.

\section{References}

$>1$ Reijmer Y, van den Berg E, Ruis C, Kappelle LJ, Biessels GJ: Cognitive dysfunction in patients with type 2 diabetes. Diabetes Metab Res Rev 2010;26:507-519.

-2 van Harten B, de Leeuw FE, Weinstein HC, Scheltens P, Biessels GJ: Brain imaging in patients with diabetes: a systematic review. Diabetes Care 2006;29:2539-2548.

-3 Jongen C, Biessels G: Structural brain imaging in diabetes: a methodological perspective. Eur J Pharmacol 2008;585:208-218.

$\checkmark 4$ Falvey CM, Rosano C, Simonsick EM, Harris T, Strotmeyer ES, Satterfield S, Yaffe K; Health ABC Study: Macro- and microstructural magnetic resonance imaging indices associated with diabetes among communitydwelling older adults. Diabetes Care 2013;36: 677-682.

$>5$ Moran C, Phan TG, Chen J, Blizzard L, Beare R, Venn A, Münch G, Wood AG, Forbes J, Greenaway TM, Pearson S, Srikanth V: Brain atrophy in type 2 diabetes: regional distribution and influence on cognition. Diabetes Care 2013;36:4036-4042.

6 Detrano R, Guerci AD, Carr JJ, Bild DE, Burke G, Folsom AR, Liu K, Shea S, Szklo M, Bluemke DA, O'Leary DH, Tracy R, Watson K, Wong ND, Kronmal RA: Coronary calci$\mathrm{um}$ as a predictor of coronary events in four racial or ethnic groups. N Engl J Med 2008; 358:1336-1345.

$>7$ Folsom AR, Kronmal RA, Detrano RC, O'Leary DH, Bild DE, Bluemke DA, Budoff MJ, Liu K, Shea S, Szklo M, Tracy RP, Watson KE, Burke GL: Coronary artery calcification compared with carotid intima-media thickness in the prediction of cardiovascular disease incidence: the multi-ethnic study of atherosclerosis (MESA). Arch Intern Med 2008; 168:1333-1339.

$>8$ Agarwal S, Cox AJ, Herrington DM, Jorgensen NW, Xu J, Freedman BI, Carr JJ, Bowden DW: Coronary calcium score predicts cardiovascular mortality in diabetes: diabetes heart study. Diabetes Care 2013;36: 972-977.

$>9$ Raggi P, Shaw LJ, Berman DS, Callister TQ: Prognostic value of coronary artery calcium screening in subjects with and without diabetes. J Am Coll Cardiol 2004;43:16631669.

10 Polonsky TS, McClelland RL, Jorgensen NW, Bild DE, Burke GL, Guerci AD, Greenland P. Coronary artery calcium score and risk classification for coronary heart disease prediction. JAMA 2010;303:1610-1616.

-11 Erbel R, Mohlenkamp S, Moebus S, Schmermund A, Lehmann N, Stang A, Dragano N,
Gronemeyer D, Seibel R, Kalsch H, BröckerPreuss M, Mann K, Siegrist J, Jöckel KH; Heinz Nixdorf Recall Study Investigative Group: Coronary risk stratification, discrimination, and reclassification improvement based on quantification of subclinical coronary atherosclerosis: the Heinz Nixdorf Recall study. J Am Coll Cardiol 2010;56:13971406.

12 Elias-Smale SE, Proenca RV, Koller MT, Kavousi M, van Rooij FJ, Hunink MG, Steyerberg EW, Hofman A, Oudkerk M, Witteman JC: Coronary calcium score improves classification of coronary heart disease risk in the elderly: the Rotterdam study. J Am Coll Cardiol 2010;56:1407-1414.

13 Hoff J, Quinn L, Sevrukov A, Lipton RB, Daviglus M, Garside DB, Ajmere NK, Gandhi S, Kondos GT: The prevalence of coronary artery calcium among diabetic individuals without known coronary artery disease. J Am Coll Cardiol 2003;41:1008-1012.

14 Hugenschmidt CE, Hsu FC, Hayasaka S, Carr JJ, Freedman BI, Nyenhuis DL, Williamson JD, Bowden DW: The influence of subclinical cardiovascular disease and related risk factors on cognition in type 2 diabetes mellitus: the DHS-Mind study. J Diabetes Complications 2013;27:422-428. 
$\checkmark 15$ Bowden DW, Cox AJ, Freedman BI, Hugenschimdt CE, Wagenknecht LE, Herrington D, Agarwal S, Register TC, Maldjian JA, Ng MC, Hsu FC, Langefeld CD, Williamson JD, Carr JJ: Review of the diabetes heart study (DHS) family of studies: a comprehensively examined sample for genetic and epidemiological studies of type 2 diabetes and its complications. Rev Diabet Stud 2010;7:188-201.

$\checkmark 16$ Bowden DW, Lehtinen AB, Ziegler JT, Rudock ME, Xu J, Wagenknecht LE, Herrington DM, Rich SS, Freedman BI, Carr JJ, Langefeld $\mathrm{CD}$ : Genetic epidemiology of subclinical cardiovascular disease in the diabetes heart study. Ann Hum Genet 2008;72(pt 5):598610.

17 Wagenknecht LE, Bowden DW, Carr JJ, Langefeld CD, Freedman BI, Rich SS: Familial aggregation of coronary artery calcium in families with type 2 diabetes. Diabetes 2001; 50:861-866.

18 Bowden DW, Rudock M, Ziegler J, Lehtinen $\mathrm{AB}, \mathrm{Xu} J$, Wagenknecht LE, Herrington D, Rich SS, Freedman BI, Carr JJ, Langefeld CD: Coincident linkage of type 2 diabetes, metabolic syndrome, and measures of cardiovascular disease in a genome scan of the diabetes heart study. Diabetes 2006;55:1985-1994.

$\checkmark 19$ Roy T, Lloyd CE, Pouwer F, Holt RI, Sartorius $\mathrm{N}$ : Screening tools used for measuring depression among people with type 1 and type 2 diabetes: a systematic review. Diabet Med 2012; 29:164-175.

20 Teng EL, Chui HC: The modified mini-mental state (3MS) examination. J Clin Psychiatry 1987;48:314-318.

21 Wechsler D: Manual for the Wechsler Adult Intelligence Scale - Revised. New York, Psychological Corporation, 1981.

22 Houx PJ, Jolles J, Vreeling FW: Stroop interference: aging effects assessed with the Stroop Color-Word test. Exp Aging Res 1993;19: 209-224.

23 Lezak M, Howieson D, Loring D: Neuropsychological Assessment. New York, Oxford University Press, 2004.

24 Benton AL, Hamsher KD, Sivan A: Multilingual Aphasia Examination. Iowa City, AJA Associates, 1994.

25 Strauss E, Sherman E, Spreen O: A Compendium of Neuropsychological Tests: Administration, Norms and Commentary. New York, Oxford Univeristy Press, 2006.

26 Luh WM, Wong EC, Bandettini PA, Hyde JS: QUIPSS II with thin-slice TI1 periodic saturation: a method for improving accuracy of quantitative perfusion imaging using pulsed arterial spin labeling. Magn Reson Med 1999; 41:1246-1254.

-27 Yang Y, Frank JA, Hou L, Ye FQ, McLaughlin AC, Duyn JH: Multislice imaging of quantitative cerebral perfusion with pulsed arterial spin labeling. Magn Reson Med 1998;39:825832.

28 Ashburner J, Friston KJ: Voxel-based morphometry - the methods. Neuroimage 2000; 11:805-821.
29 Jenkinson M, Beckmann CF, Behrens TE, Woolrich MW, Smith SM: FSL. NeuroImage 2012;62:82-90.

30 Maldjian JA, Laurienti PJ, Burdette JH, Kraft RA: Clinical implementation of spin-tag perfusion magnetic resonance imaging. J Comput Assist Tomogr 2008;32:403-406.

31 Johnston ME, Zheng Z, Maldjian JA, Whitlow CT, Morykwas MJ, Jung Y: Cerebral blood flow quantification in swine using pseudocontinuous arterial spin labeling. J Magn Reson Imaging 2013;38:1111-1118.

32 Watts JM, Whitlow CT, Maldjian JA: Clinical applications of arterial spin labeling. NMR Biomed 2013;26:892-900.

\33 Powers WJ, Grubb RL Jr, Darriet D, Raichle ME: Cerebral blood flow and cerebral metabolic rate of oxygen requirements for cerebral function and viability in humans. J Cereb Blood Flow Metab 1985;5:600-608.

- 34 Schmidt P, Gaser C, Arsic M, Buck D, Forschler A, Berthele A, Hoshi M, Ilg R, Schmid VJ, Zimmer C, Hemmer B, Mühlau M: An automated tool for detection of FLAIRhyperintense white-matter lesions in multiple sclerosis. Neuroimage 2012;59:3774-3783.

- 35 Maldjian JA, Whitlow CT, Saha BN, Kota G, Vandergriff C, Davenport EM, Divers J, Freedman BI, Bowden DW: Automated white matter total lesion volume segmentation in diabetes. AJNR Am J Neuroradiol 2013;34: 2265-2270.

- 36 Vidal JS, Sigurdsson S, Jonsdottir MK, Eiriksdottir G, Thorgeirsson G, Kjartansson O, Garcia ME, van Buchem MA, Harris TB, Gudnason V, Launer LJ: Coronary artery calcium, brain function and structure: the AGES-Reykjavik study. Stroke 2010;41:891897.

37 Rosano C, Naydeck B, Kuller LH, Longstreth WT Jr, Newman AB: Coronary artery calcium: associations with brain magnetic resonance imaging abnormalities and cognitive status. J Am Geriatr Soc 2005;53:609-615.

38 Gianaros PJ, Greer PJ, Ryan CM, Jennings JR: Higher blood pressure predicts lower regional grey matter volume: consequences on short-term information processing. Neuroimage 2006;31:754-765.

39 Qiu C, Sigurdsson S, Zhang Q, Jonsdottir MK, Kjartansson O, Eiriksdottir G, Garcia ME, Harris TB, van Buchem MA, Gudnason V, Launer LJ: Diabetes, markers of brain pathology and cognitive function: the Age, Gene/ Environment Susceptibility-Reykjavik study. Ann Neurol 2014;75:138-146.

40 Espeland MA, Bryan RN, Goveas JS, Robinson JG, Siddiqui MS, Liu S, Hogan PE, Casanova R, Coker LH, Yaffe K, Masaki K, Rossom R, Resnick SM; WHIMS-MRI Study Group: Influence of type 2 diabetes on brain volumes and changes in brain volumes: results from the Women's Health Initiative Magnetic Resonance Imaging studies. Diabetes Care 2013; 36:90-97.

41 Schmidt R, Ropele S, Enzinger C, Petrovic K, Smith S, Schmidt H, Matthews PM, Fazekas
F: White matter lesion progression, brain atrophy, and cognitive decline: the Austrian stroke prevention study. Ann Neurol 2005;58: 610-616.

42 Reijmer YD, van den Berg E, de Bresser J, Kessels RP, Kappelle LJ, Algra A, Biessels GJ; Utrecht Diabetic Encephalopathy Study Group: Accelerated cognitive decline in patients with type 2 diabetes: MRI correlates and risk factors. Diabetes Metab Res Rev 2011;27: 195-202.

-43 Muller M, Appelman AP, van der Graaf Y, Vincken KL, Mali WP, Geerlings MI: Brain atrophy and cognition: interaction with cerebrovascular pathology? Neurobiol Aging 2011;32:885-893.

44 Verdelho A, Madureira S, Moleiro C, Ferro JM, Santos CO, Erkinjuntti T, Pantoni L, Fazekas F, Visser M, Waldemar G, Wallin A, Hennerici M, Inzitari D; LADIS Study: White matter changes and diabetes predict cognitive decline in the elderly: the LADIS study. Neurology 2010;75:160-167.

45 Madhavan KM, McQueeny T, Howe SR, Shear P, Szaflarski J: Superior longitudinal fasciculus and language functioning in healthy aging. Brain Res 2014;1562:11-22.

46 Laukka EJ, Lövdén M, Kalpouzos G, Li TQ, Jonsson T, Wahlund LO, Fratiglioni L, Bäckman L: Associations between white matter microstructure and cognitive performance in old and very old age. PLoS One 2013;8: e81419.

47 Richard Jennings J, Christie IC, Muldoon MF, Ryan CM, Price JC, Meltzer CC: Brain function, cognition, and the blood pressure response to pharmacological treatment. Psychosom Med 2010;72:702-711.

-48 Launer LJ, Miller ME, Williamson JD, Lazar RM, Gerstein HC, Murray AM, Sullivan M, Horowitz KR, Ding J, Marcovina S, Lovato LC, Lovato J, Margolis KL, O'Connor P, Lipkin EW, Hirsch J, Coker L, Maldjian J, Sunshine JL, Truwit C, Davatzikos C, Bryan RN; ACCORD MIND Investigators: Effects of intensive glucose lowering on brain structure and function in people with type 2 diabetes (ACCORD MIND): a randomised open-label substudy. Lancet Neurol 2011;10:969977.

49 Swan GE, DeCarli C, Miller BL, Reed T, Wolf PA, Jack LM, Carmelli D: Association of midlife blood pressure to late-life cognitive decline and brain morphology. Neurology 1998;51:986-993.

50 Vernooij MW, Ikram MA, Vrooman HA, Wielopolski PA, Krestin GP, Hofman A, Niessen WJ, Van der Lugt A, Breteler MM: White matter microstructural integrity and cognitive function in a general elderly population. Arch Gen Psychiatry 2009;66:545553.

51 Bauer DJ, Preacher KJ, Gil KM: Conceptualizing and testing random indirect effects and moderated mediation in multilevel models: new procedures and recommendations. Psychol Methods 2006;11:142-163.
Association between Cognitive Testing, Imaging and Subclinical CVD
Neuroepidemiology 2015;45:1-11 DOI: $10.1159 / 000435775$ 